Association for Information Systems AIS Electronic Library (AISeL)

December 2004

\title{
Can Technology Build Organizational Social Capital: The Case of a Global IT Consulting Firm
}

\author{
Karma Sherif \\ Texas Tech University \\ James Hoffman \\ Texas Tech University \\ James Wetherbe \\ Texas Tech University
}

Follow this and additional works at: http://aisel.aisnet.org/amcis2004

\section{Recommended Citation}

Sherif, Karma; Hoffman, James; and Wetherbe, James, "Can Technology Build Organizational Social Capital: The Case of a Global IT Consulting Firm" (2004). AMCIS 2004 Proceedings. 279.

http://aisel.aisnet.org/amcis2004/279 


\title{
Can Technology Build Organizational Social Capital: The Case of a Global IT Consulting Firm
}

\author{
Karma Sherif \\ Texas Tech University \\ Karma.sherif@ttu.edu
}

\author{
James Hoffman \\ Texas Tech University \\ hoffman@ba.ttu.edu
}

\author{
James Wetherbe \\ Texas Tech University \\ jwetherbe@ba.ttu.edu
}

\begin{abstract}
Knowledge Management (KM) and Knowledge Management Systems (KMS) have been positioned as strategies and tools that enable organizations to create and transfer knowledge in order to sustain competitive advantage. While Knowledge Management as a strategy was able to gain legitimacy, KMS struggled to prove a causal relationship to knowledge creation and knowledge transfer. KMS contribution to the economic performance of organizations has been harder to prove mainly because of a lack in the collection and analysis of knowledge metrics. This has lead to unjustifiable move within the KM community to underplay the role of technology especially in the case of knowledge creation and transfer. In this paper, we attempt to revive interest in KMS by exploring KMS ability to accumulate social capital and its effect on the creation and transfer of knowledge. We pose social capital as the mediating factor between KMS and knowledge creation and transfer and theorize that (1) KMS will positively affect an organization's ability to build up social capital, and that (2) social capital will enhance a firm's ability to create and transfer knowledge. Qualitative data collected from a multinational IT consulting firm, that have successfully implemented a KMS as the main channel for developers to create and transfer knowledge, is used to validate the framework.
\end{abstract}

\section{KEYWORDS}

Knowledge Management, Knowledge Management Systems, Social Capital, Qualitative Study.

\section{INTRODUCTION}

For the last decade, Knowledge Management (KM) (Davenport and Prusak 1998) and Knowledge Management Systems(KMS) (Alavi and Leidner 2000) have been positioned as vehicles for the creation and transfer of knowledge within organizations (Holsapple and Joshi 1997), a capacity recognized as the main source of sustained competitive advantage (Grant 1996). KM, being the large umbrella, defines a strategy for managing knowledge that includes people, processes, and technology for creating, capturing, categorizing, disseminating, and using knowledge to generate value to the organization (Davenport et. al. 1998, Massey et. al. 2001, Hansen et. al. 1999, Zack 1999). KMS provided a medium for exchange but had difficulty claiming any positive effects on the creation of knowledge. As a result, KM started focusing on the role of other elements of its strategy, like culture and processes, and underplayed the role of KMS. To date, there is no clear and cohesive theoretical framework that can provide a structure for analysis and a lens through which to assess the relationship between KMS and organizational capacity to create and transfer knowledge.

The objective of this study is to shed light on the role KMS plays in the accumulation of social capital and its effect on the creation and transfer of knowledge organizations. Social capital has been proven to enhance a firm's "speed and efficiency in the creation and transfer of knowledge" (Kogut and Zander 1996 p. 503) and thus has the potential to impact an organization's ability to improve performance. Our central proposition is that KMS is a valuable resource for developing networks of social relationships and providing access to a "collectively-owned capital" of knowledge that is capable of creating new knowledge, sustaining competitive advantage and improving economic performance. While we still agree with the lack of a direct relationship between KMS and knowledge creation and knowledge transfer, we believe social capital to be the mediating factor that better explains that relationship. Our main research questions are: 1) can KMS accumulate social capital? and 2) does the accumulation of social capital facilitate the creation and sharing of new knowledge. We use data 
collected from a global IT consulting firm that have successfully implemented a KMS as the main channel for developers to create and transfer knowledge to validate our framework.

This paper is organized as follows: section two defines Knowledge Management Systems(KMS) and surveys its several applications; section three explains the various dimensions of social capital; section four demonstrates how a KMS can accumulate social capital and develops a theoretical framework that hypothesizes a positive relationships between the use of KMS and the accumulation of the three dimensions of social capital; section four covers our research design; section five discusses the findings; and the paper concludes with a tribute to KMS as a facilitator for the accumulation of social capital.

\section{KNOWLEDGE MANAGEMENT SYSTEMS}

Knowledge Management Systems (KMS) are defined as "A class of information systems applied to managing organizational knowledge....they are IT-based systems developed to support and enhance the organizational processes of knowledge creation, storage/retrieval, transfer and application." (Alavi and Leidner 2001 p. 114). The three common uses of IT in KM has been storage of lessons learned, access to expertise within the organization and the creation of knowledge networks (Davenport and Prusak 1998). IT storage and networking capabilities enabled it to build large electronic communities that embed huge knowledge resources made available to its member. The scope of these networks guarantees a level of diversity that entitles such networked communities to a rich pool of "collectively-owned" knowledge that members can draw from the virtual space. Such diversity enhances the capacity of organizations to combine and integrate pieces of knowledge into innovative solutions.

The use of hypermedia has enabled the development of highly interconnected pieces of knowledge, a key factor of innovation and the creation of new knowledge. The ease of updating and linking assets within a KMS has the profound impact of mitigating the risk of collective blindness from group think. New ideas that are shared across the network are likely to result in a higher adoption rate than a less networked community. KMS are also able to store, display and exchange rich multimedia files that can be shared among members of the network at real time to support the transfer of highly tacit knowledge. Examples of such systems are popular in the oil and gas industry where visualization software is used to transfer the highly tacit knowledge of an expert (Davenport and Prusak 1998). The ability to annotate video clips with comments that highlight reflections on "know-how" and "know-why" facilitates embedding knowledge within electronic files discrediting arguments that KMS can not store or exchange tacit knowledge. Even in areas that are highly recognized for tacit knowledge, like deception detection, KMS technology assisted in the transfer of expert tacit knowledge without the need for face-to-face intervention (Lin et. al. 2003). In fact the structure imposed in electronic training within a KMS is capable of shaping individual experience to specifically internalize tacit knowledge that would have taken a longer period of time to internalize within naturally occurring social settings.

Despite the above-mentioned advancement in KM technologies, KMS is still struggling to prove a causal relationship to knowledge creation and knowledge transfer. The main reason behind the struggle has been attempts to draw direct relationships between KMS and creation and transfer of knowledge. We agree that the technology in itself lack that capability. It has to be supported by strategies, roles, processes and culture to be able to affect knowledge creation and knowledge transfer. It is these resources that members of a community draw upon to create and transfer knowledge. In this paper, we focus on the ability of KMS to accumulate social capital; an organizational resource that facilitates the creation and transfer of knowledge. So while, the technology cannot, by itself, foster innovation and knowledge sharing, it certainly facilitates the development of underlying mechanisms that lead to knowledge creation and knowledge transfer.

\section{SOCIAL CAPITAL}

Social capital is "the sum of the actual and potential resources embedded within, available through, and derived from the network of relationships possessed by an individual or social unit. Social capital, thus, comprises of both the network and the assets that may be mobilized through that network" (Nahapiet and Ghoshal 1998 p. 243). Members of communities with a substantial stock of social capital find it much easier to exchange knowledge and collaborate to create new knowledge because of the existence of trust and social norms (Coleman, 1988). The literature suggests that social capital can be defined along three dimensions: structural; relational; and cognitive (Nahapiet and Ghoshal 1998). Listed below are the separate dimensions and a more complete description of their makeup.

\section{The structural dimension of social capital}

This dimension refers to the information channels that connect individuals and units. They serve as social networks within the organization and also as mechanisms for connecting to the outside world. Through high levels of this dimension of social capital, members of the organization can gain direct access to knowledge privately possessed in the network (Portes, 1998). 
Facets of this dimension include the presence or absence of network ties and network configuration. Network configuration refers to the density, connectivity, hierarchy and adaptability of a network. The structural dimension is the directly observable inventory of social capital.

\section{The relational dimension of social capital}

It refers to the assets created and leveraged through relationships. As individuals develop relationships through a history of social interaction, they build up assets that they can draw upon in their day-to-day activities. They develop high levels of trust and reciprocity that engender higher levels of interaction and knowledge transfer (Putnam, 1993).

Within a network, obligations and expectations lead to collective trust, which becomes a potent form of social asset (Knez \& Camerer, 1994; Nahapiet \& Ghoshal, 1998). Collective trust allows group members to rely on each other more generally to help solve the everyday problems of cooperation and coordination (Kramer, Brewer \& Hanna 1996). With collective trust present, group members can rely on one another to follow through with things expected of them and obligations owed by them. Group members are then more willing to work for the group with the knowledge and expectation that the group will work for them when the time comes.

Identity occurs when individuals see themselves as one with another person or group of people (Nahapiet \& Ghoshal, 1998). The individual takes the values or standards of other individuals or groups as a comparative frame of reference (Merton, 1968; Tajfel, 1982). Identity with a group enhances concern for collective processes and outcomes, thus increasing and strengthening group norms and collective goals. In contrast, where identity is not present there are significant barriers to information sharing, learning, and knowledge creation (Child \& Rodriques, 1996; Pettigrew, 1973; Simon \& Davies, 1996).

\section{The cognitive dimension of social capital}

The cognitive dimension of social capital engages in emerging a shared meaning and a shared understanding of the purpose of the networked community along with a common understanding of the domain of focus of the community. Through interaction, a common frame of reference starts to surface providing a shared language for group communication. Elements of the language dominate the content of communicative messages among members. In addition to the common language, a shared narrative is exchanged whose underlying ground truths are unprovoked by members of the community. The narratives are used to make analogies to the past and to shorten the learning curve of new members joining the community. The common language and the shared language, both, help to strengthen the identity of the community.

\section{KNOWLEDGE MANAGEMENT SYSTEMS AND SOCIAL CAPITAL}

As mentioned above, to date there is no clear and cohesive theoretical framework that can provide a structure for analysis and a lens through which to assess the effect of KMS on an organization's capacity to create and transfer knowledge. We know from prior research that some organizations which adopt KMS appear to be able to effectively create and transfer knowledge better than others (Jennex and Olfman 2003), but the underlying mechanism that creates this capability has been unclear. This article proposes that the underlying mechanism that creates the capability is social capital. While studies in management have argued that social capital explains the creation and transfer of knowledge, we argue that KMS help accumulate social capital, which in turn contribute to the creation and sharing of knowledge. The main thesis we develop here is that KMS allow for relationships and exchanges to occur; both have been identified as preconditions for building up social capital (Bourdieu 1986). To explore this proposition, we explore some of the ways in which KMS technology influence each of the three dimensions of social capital enabling organizations to create and transfer knowledge (See Figure 1). Despite the focus on KMS, we still maintain the view that success in the adoption of any technology will need the support of other factors like strategies, organizational structure, processes, and change management. 


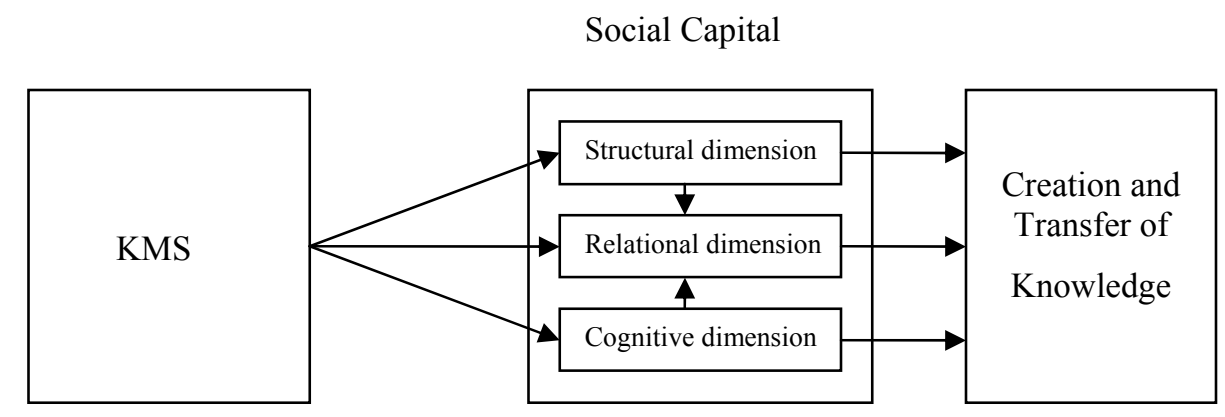

Figure 1. A Model of KMS, Social Capital and Creation and Transfer of Knowledge

\section{KMS and the structural dimension}

One of the highly developed features of a KMS is its network capacity. Sophisticated forms of electronic communities can be created and maintained using underlying technology of KMS. Our main argument in this section is that, KMS influence the development of the structural dimension of social capital primarily through the ways in which the network layer of KMS enables the formation of virtual communities for members of the organization to exchange knowledge and build relationships. Communication software like email, discussion groups, and chat rooms enable close social interaction between members who get to evolve a shared understanding of the goals and objectives of the community, and to asses the trustworthiness and expertise of others in the community. An actor, a group, or a business unit, who has numerous ties with others in the community, occupies a central location in a virtual community. Centrality of an actor or a business unit has been empirically verified to be positively associated with perceived trustworthiness (Tsai and Ghoshal 1998).

Based on the earlier discussion we hypothesize that:

Hypothesis 1: The use of Knowledge Management Systems will be positively associated with the ability of members of a community to occupy a central location on the network.

\section{KMS and the relational dimension}

The development of the structural dimension of social capital leads to the development of the relational as well as cognitive dimensions. The relational dimension is associated with building trust among members of the community, developing the norms for interaction, setting the expectations and obligations of members and creating a distinctive identity of the community that members readily associate with. Though no empirical tests exist for the effect of KMS on the level of trust, definition of norms, obligations and expectations, and the creation of an identity, anecdotal studies point to the positive effect of KMS on facets of the relational dimension of social capital. IBM Global Services (Gongla and Rizzuto 2001) reported that usage of electronic communities of practice fostered the development of trust-based relationships because members are able to gain detailed knowledge about one another from captured discussions in email messages, discussion boards and electronic chat rooms. Issue-based discussion facility (Huang 1998) captured brain storming sessions and arguments that led to decisions. The feature was particularly valuable because it provided members with a decision rationale and a higher level of trust in reusing explicit knowledge embedded within the network. In a study of seven large organizations, electronic communities were able to foster trust and obligations (Lesser and Storck 2001). In these shared spaces, individuals began to evaluate who was making contributions to the greater community knowledge pool, and they began to judge the willingness of others to share the documents templates, and other similar knowledge artifacts. Automatic tracking tools (Huang 1998) enabled communities to measure effectiveness and identify gaps within knowledge bases through monitoring knowledge activities and identifying reusable intellectual capital. Besides recognizing original sources of knowledge, the tool enables the community and the organization as a whole to assign reward credits based on the magnitude and value of contributions. Recognition and credit assignment are believed to build trust and receptiveness to share in organizations (Davenport and Prusak 1998). 
As members of the community determine what is important and how they'll function, they develop a sense of identity. The identity makes it possible for the community to distinguish itself from others within the organization. As members work to create and leverage knowledge that is important to the community, they reinforce the identity. A special tool within the KMS that help reinforce the community's identity is a community portal. The portal provides an abstract view of what the community is all about. It is very common for these portals to list the mission for their communities on their welcoming page. Besides asserting the identity of the community, portals can be personalized to adapt to individual or group preferences, giving rise to sub cultures within the larger community.

Based on the above discussion we hypothesize that

Hypothesis 2: The use of Knowledge Management Systems will be positively associated with the ability of members of a community to trust each other.

Hypothesis 3: The use of Knowledge Management Systems will be positively associated with the ability of members of a community to evolve social norms that govern their interaction.

Hypothesis 4: The use of Knowledge Management Systems will be positively associated with the ability of members of a community to define expectations and obligations.

Hypothesis 5: The use of Knowledge Management Systems will be positively associated with the ability of members of a community to develop an identity for the community they identify themselves with.

\section{KMS and the cognitive dimension}

As the community establishes its common identity, the members begin creating a shared frame of reference. Members learn to communicate with one another using a common vocabulary. The vocabulary is reinforced in a KMS taxonomy and knowledge base category structure. The taxonomy demonstrates important concepts to the community and provides new comers an abstract view of the domain of focus. Messages and discussions exchanged among members of the community use the common vocabulary to represent issues, as well as, solutions. Repositories are also able to capture community's stories that glue pieces of the group memory together and help new members make sense of the stored content. Based on the above discussion we hypothesize that

Hypothesis 6: The use of Knowledge Management Systems will be positively associated with the ability of members of a community to evolve a common language of their domain of focus.

\section{RESEARCH METHOD}

To validate the research model, a case study in a multinational IT consulting firm was conducted. The research site was identified from the Knowledge Management literature where it was recognized as a pioneer in knowledge management and the recipient of several awards for its knowledge management system, the K-WEB. Twenty participants were interviewed and asked about their perceptions and beliefs regarding the K-WEB in place. We sliced vertically within the knowledge management and the IT consulting organizations and selected members at different organizational levels. We interviewed consultants and knowledge managers that came from three different organizational levels: Top management; middle management and front-liners. From the knowledge management side, we interviewed the Chief Knowledge Officer (CKO) for the company as a whole, the CKO for the Americas, the knowledge managers for the telecommunication and the oil and gas sectors, and several knowledge workers that worked at the project level. Within IT consulting, we interviewed telecommunication sector manager, several senior project managers and senior and staff consultants who worked on individual and collaborative assignments. The questions were general open-ended questions to enable the participants to express freely their ideas without gauges from the research team as to what we consider important constructs. Interviews ranged from 45 to 90 minutes and were all taped. The study lasted for a period of six months.

\section{Data analysis}

The data analysis effort started by reading the interviews and categorizing the text under one of the a priori codes we borrowed from social capital. The codes were categorized under three major categories: the structural; the relational and; the cognitive dimensions. The categories and the definition of corresponding codes appear in Table 1. 
Two researchers, one of whom was blind to the research hypotheses, coded the data. We applied the semiotic mode following Krippendorff's (1980) approach to content analysis, in which words from the interviews were assigned to one of the 3 highlevel categories and further categorized under one of the codes. The focus was not on the meaning of the comment but rather on the type of comments made. In an effort to increase Inter-rater reliability, the researchers came with a set of cues that would help the coders consistently categorize similar quotes under the same code. The researchers reviewed their coding to resolve conflicts in understanding the data and the meaning attached to it. The inter-rater reliability reached $100 \%$ towards the end of the analysis phase.

\begin{tabular}{|c|c|c|}
\hline Category & Code & Meaning \\
\hline \multirow[t]{3}{*}{ Structural Dimension } & Network ties and connectivity & $\begin{array}{l}\text { Ability to communicate and build } \\
\text { relationships with others }\end{array}$ \\
\hline & Density & frequency of communication \\
\hline & Adaptability & $\begin{array}{l}\text { Ability of the network to } \\
\text { reconfigure itself }\end{array}$ \\
\hline \multirow[t]{5}{*}{ Relational Dimension } & Social Norms & $\begin{array}{l}\text { Beliefs about how people should } \\
\text { behave within the organization }\end{array}$ \\
\hline & Obligations and expectations & $\begin{array}{l}\text { The duties of each individual and } \\
\text { what they can expect from others }\end{array}$ \\
\hline & Trust & $\begin{array}{l}\text { The level of trust among } \\
\text { members }\end{array}$ \\
\hline & Reputation & $\begin{array}{l}\text { The reputation that people or } \\
\text { knowledge gets depending on the } \\
\text { experience people have or the } \\
\text { quality of knowledge }\end{array}$ \\
\hline & Identity & $\begin{array}{l}\text { How people identify themselves } \\
\text { with a particular line of business }\end{array}$ \\
\hline \multirow[t]{2}{*}{ Cognitive Dimension } & Common language & $\begin{array}{l}\text { Common keywords that people } \\
\text { use to communicate or retrieve } \\
\text { information }\end{array}$ \\
\hline & Shared narrative & Stories that people share \\
\hline
\end{tabular}

Table 1. CATEGORIES AND CODES USED FOR CODING

\section{FINDINGS AND DISCUSSION}

The analysis of the qualitative data confirmed all six hypotheses. Members of the knowledge management organization and IT consultants strongly believed that the K-WEB enabled them to build a well-connected, dense, and highly adaptable network that helped the organization promote its social norms, establish a set of responsibilities and foster trust. Members of the network shared a common language embedded in the knowledge assets and stories hosted within the repository and in threaded discussion captured within their virtual communities.

\section{The $\mathrm{K}-\mathrm{WEB}$}

The infrastructure for the K-WEB is based on Lotus Notes ${ }^{\circledR}$ and dates back to 1982. In 1992, Business Week rated it as one of the best tools in the area of Knowledge Management. The goal of the knowledge management program has always been to provide content "anytime, anyplace, using any type of computing device."

The company is developing a portal for all seven sectors as the single point of entry to the knowledge repository. The objectives for the portal are: provide homogeneity for all of the knowledge management systems, allow both passive and 
interactive communication with the end-user seeking access to the content, and enable users to navigate, search, and retrieve specific details that are of interest and relevance to the user. An important aspect of the design of the portal is the shielding of the end user from the complexity of where the information resides or how it is maintained. The portal will route users to internal communities or to third party information service providers. Third party information will also be available on a subscription basis through contracts with various content aggregators like the Gartner Group. In addition to content, the portal will also provide a directory of experts within sectors across the 9 regions.

\section{The Structural Dimension of the K-WEB}

Consultants, and knowledge workers alike, believed that the k-web help them get better connected to members of the global organization and especially those that work within the same sector. The communication tools within K-WEB helped consultants and knowledge workers to seek or contribute knowledge to members of the larger organization whom they never communicated face to face. The information channels created strong ties between members that helped them establish a sense of identity to the sector and a level of trust to share and reuse. The following comment demonstrates the structural dimension of the KWEB

"I know that there is valuable information on Mobile Commerce in Europe and I got to see what they have done out there because there's nothing really strong here in the U.S. from my perspective. So the tools are very valuable right now. I think that the contributions from all over the world that are being made to the Mobil Commerce knowledge base system have been outstanding. There is much more of a true global give and take now"

We thus conclude that the knowledge management system helped members of the organization to occupy a central location within the network developed for each sector.

\section{The Relational Dimension of the K-WEB}

The K-WEB helped the organization establish several social norms that sustained the knowledge management efforts to share and create new knowledge. Among these social norms are: "knowledge is power;" "leverage knowledge on a daily basis;" "reach out and ask for help;" The norms are part of the messages that the K-WEB help to engrave as part of the individual values of organizational members at all organizational levels. The norms created obligations within the virtual community that members need to leverage knowledge that already exists and ask for help if they can't locate meaningful information. The postings of the knowledge assets on the K-WEB along with their creators and the experience of the reusers help enforce the social norms and create expectations around them. The following story highlights the obligation "reach-out" that emerged from using the knowledge management systems.

"To give you an example an individual was from the real estate industry but I needed for him to do a particular job in Telecom. He had to apply his CRM skill from real estate and transfer it over for telecom. There is specific information about the telecom that he has to understand. He didn't reach out to the telecom specific type things and so it cost him. Because he wasn't reaching out and using the network, it was a mistake on his part."

Specific features within the K-WEB helped reinforce the obligations. One of these features is an alert functionality for the exclusive use of the sector knowledge managers. The functionality alerts the manager when a project starts, and provides the name of the project knowledge manager (the person to be contacted to encourage the team to submit their deliverables to the KWEB or to reuse other relevant knowledge assets). The system will also alert a sector knowledge manger when a deliverable is submitted to a customer, so the manager can follow-up on its submission to the K-WEB.

A feature that helped build trust among members of a sector is the automatic tracking feature within K-WEB that keeps track of the assets submitted and the level of reuse for each asset. The tool enables managers to award "special recognition for those who contribute heavily to knowledge bases." It also builds reputation for those who contribute valuable knowledge assets.

\section{The Cognitive Dimension and the K-WEB}

The frequent use of the K-WEB led to the emergence of a common language among members of the same sector. The local languages were embedded within the knowledge assets and threaded discussions within the virtual communities as evident from the quote 
"she has spent enough time and energy reading and contributing to the discussions within utilities that she knows all the jargon so there is no comparison, I mean, she is three times as productive as somebody who may be more experienced as a business researcher, but doesn't know anything about the oil industry."

The K-WEB also captured stories within each sector that recounted experiences with important clients.

"She put together something a story of our company at XY Corporation. The stories help us know and understand what we do and give us a history of relationships. They also help us out when we're trying to sell work to a client."

\section{SUMMARY AND CONCLUSION}

In this paper, we shed light on the role KMS plays in the accumulation of social capital and its effect on the creation and transfer of knowledge. We argue that knowledge management systems help organizations accumulate all three dimensions of social capital: structural; relational; and cognitive. It creates a dense and highly connected network, whose members trusts each other and feels obliged to carryout the responsibilities bestowed on them by the network that they associate with. The network emerges a common language between members that recounts the stories shared by members of the network. We developed a theoretical framework and three sets of hypotheses that propose positive relationships between the use of KMS and social capital. We used data from a multinational consulting firm to validate the framework.

\section{REFERENCES}

1. Alavi, M. and Leidner, D. (2001) Review: Knowledge Management and Knowledge Management Systems: Conceptual Foundations and Research Issues. MIS Quarterly 25,1, 107-136.

2. Bourdieu, P. (1986) The forms of social capital. In J. G. Richardson (Ed.),Handbook of theory and research for the sociology of education: 241-258. New York: Greenwood.

3. Child, J., \& Rodriques, S. (1996) The role of social identity in the international transfer of knowledge through joint ventures. In S. R. Clegg \& G. Palmer (Eds.), The politics of management knowledge: 46-68. London: Sage.

4. Coleman, J. S. (1988) Social capital in the creation of human capital. American Journal of Sociology. 94, 95-120.

5. Davenport, T.H. and Prusak, L. (1988) Working Knowledge: How Organizations Manage What They Know. Harvard Business School Press, Boston, Mass.

6. Davenport, T.H.; De Long, D.W. and Beers M.C. (1998) Successful knowledge management projects. MIT Sloan Management Review. Cambridge: 39, 2, 43-58.

7. Grant, R.M. (1996) Toward a knowledge-based theory of the firm. Strategic Management Journal. Chichester 17, 109123.

8. Gongla, P. and C. R. Rizzuto (2001) Evolving communities of practice: IBM global services experience. IBM Systems Journal, 40,4, 842-862.

9. Hansen, M.T.; Nohria, N and Tierney, T. (1999) What's your strategy for managing knowledge? Harvard Business Review. 77, 2, 106-117

10. Holsapple, C.W., \& Joshi, K.D. (2002) Knowledge Management: A Threefold Framework Information Society, 2002, 47-64.

11. Jennex M., L. Olfman, (2003) A Knowledge Management Success Model: An Extension of Delone and Mclean's IS Success Model Ninth Americas Conference on Information Systems, 2529-2540.

12. Knez, M. \& Camerer, C. (1994) Creating expectational assets in the laboratory: Coordination in 'weakest link' games. Strategic Management Journal. 15, 101-119.

13. Kogut, B. Zander, U. (1996). What firms do? Coordination, identity, and learning. Organization Science. 7,5, 502-518.

14. Kramer, R. M., Brewer, M. B., \& Hanna, B. A. (1996). Collective trust and collective action: The decision to trust as a social decision. In R. M. Kramer \& T. R. Tyler (eds.) Trust in organizations. Frontiers of theory and research, 357-389. Thousand Oaks CA: Sage.

15. Krippendorff, K. (1980) Content Analysis: An Introduction to its Methodology, Sage Publications, Beverly Hills.

16. Lesser, E.L., and J. Storck (2001) Communities of Practice and Organizational Performance. IBM Systems Journal, 40,4, 831-841.

17. Lin, M., Crews, J. M., Cao, J., Nunnamaker, J. F., Burgoon, J. K.(2003) AGENT99 Trainer: Designing a Web-Based Multimedia Training System for Deception Detection Knowledge Transfer Ninth Americas Conference on Information Systems, $2563-2572$.

18. Massey, A.P., Montoya-Weiss, M.M., \& O'Driscoll, T.M. (2002) Knowledge Management in Pursuit of Performance: Insights From Nortel Networks MIS Quarterly 26,3, 269-289. 
19. Merton, R. K. (1968, First Published in 1948). Social Theory and Social Structure. New York: Free Press.

20. Nahapiet, J. and S. Ghoshal (1988) Social capital, intellectual capital, and the organizational advantage Academy of Management Review, 23,2, 242-266.

21. Pettigrew, A. M. (1973). The politics of organizational decision-making. London: Tavistock.

22. Portes, A. (1998) Social capital: Its origins and applications in modern sociology Annual Review of Sociology, 24, 1-25.

23. Putnam, R. D. (1995). Bowling alone: America's declining social capital. Journal of Democracy. 6,65-78.

24. Simon, L., \& Davies, G. (1996). A contextual approach to management learning. Organization Studies. 17, $269-289$.

25. Tajfel, H. (ed.). (1982). Social relations and intergroup relations. Cambridge University Press.

26. Tsai, W., Ghosal, S. (1998) Social Capital and Value Creation: the Role of Inter-firm Networks Academy of Management Journal $41,4,464-476$.

27. Zack, M.H. (1999) Managing codified knowledge. MIT Sloan Management Review. Cambridge: Summer. 40, 4, 45-59. 